\title{
CHARACTERISTICS OF INTERNET USE AMONGST ITALIAN UNIVERSITY STUDENTS
}

\author{
Donatella Marazziti ${ }^{1}$, Stefano Baroni ${ }^{1}$, Federico Mucci $^{1}$, Armando Piccinni ${ }^{1}$, Alberto Ghilardi ${ }^{2}$, \\ Andrea Fiorillo $^{3}$, Gabriele Massimetti ${ }^{1}$, Mario Luciano ${ }^{3}$, Gaia Sampogna ${ }^{3}$, \\ Ilenia Moroni ${ }^{1} \&$ Liliana Dell'Osso ${ }^{1}$ \\ ${ }^{I}$ Dipartimento di Medicina Clinica e Sperimentale, University of Pisa, Pisa, Italy \\ ${ }^{2}$ SSD Psicologia Clinica e Dinamica, Dipartimento di Scienze Cliniche e Sperimentali (DSCS), \\ University of Brescia, Brescia, Italy \\ ${ }^{3}$ Dipartimento di Salute Mentale e Fisica e Medicina Preventiva, University of Naples, Naples, Italy
}

received: 30.3 .2018 ;

revised: 24.10.2019;

accepted: 29.1 .2020

\section{SUMMARY}

Background: Problematic Internet use (PIU), that may be defined as the inability to control one's use of Internet with negative consequences in daily life, is an emerging problem involving primarily, but not only young generations. Different studies have shown that students are particularly vulnerable to PIU. Given the paucity of information on PIU in our country, the aim of this paper was at investigating the characteristics of PIU amongst Italian University students.

Subjects and methods: A self-assessment questionnaire, referred by the acronym QUNT ("Questionario sull'Utilizzo delle Nuove Tecnologie"), composed by 101 items grouped together to identify a series of factors, was developed and sent through e-mail invitation to several students from three Italian Universities.

Results: The returned questionnaires were 3324, out of a total of 51,304 sent, with no difference between the two sexes. On the contrary, the distribution of the QUNT factors was different in the two sexes, in people living alone and in overweight subjects. Men resulted to be more involved in online recreational activities, whereas women seemed more attracted to instant messaging and generally to social networks. PIU was significantly more present in men than women. The comparisons of QUNT factor scores in the four BMI categories showed that the greater the BMI the greater the score of some factors.

Conclusions: The findings of the present study indicate that the use of Internet through new technologies may exceed its real utility amongst Italian university student, with some sex-related differences. Men seem more prone to use Internet for passing time and women for social relationships. Men are also at risk of developing PIU. Again, Internet use might be a basic vulnerability factor of increasing weight gain and obesity amongst young people.

Key words: new technologies- Internet - social network - problematic social media use - university students

\section{INTRODUCTION}

Problematic Internet use (PIU) or Internet addiction is a behavioral addiction that is attracting increasing attention and warning given the wide spread of Internet everywhere (Christakis 2010). It has been included in the section 3 of DSM-5, reserved to conditions that require further research before they can be formally considered 'full disorders' (Block 2008, American Psychiatric Association 2013, Kuss et al. 2014). Indeed, while the Internet became commercially available in the early 1990s and is relatively young, in comparison to abuse drugs, only recently it has been considered a major treat to society due to its addictive nature. According to the Internet World Stats, Pigdom, a society that features up to date world Internet usage, population statistics and other issues (Miniwatts 2017), it was estimated that at the end of June 2017 more than $7,500,000,000$ of the world's population uses the Internet. With no doubt, we cannot disregard that Internet has promoted the rapid and easy access to any kind of information, while representing an extraordinary tool to communicate and even to entertain (Valkenburg \& Peter 2011, Ryan et al. 2014). In any case, for too many people, and especially younger generations, the so-called digital natives who are exposed since their infancy to Internet tools to play, communicate and interact, Internet is no more a tool, but a scope, sometimes the sole scope of everyday life and, as such, it may become an addiction (Council On Communications \& Media 2016, Reid Chaissakos et al. 2016).

The term Internet addiction was conied ironically in 1995 by Ivan Goldberg a newyorker psychiatrist to label those individuals who declared to use Internet between 8 and 60 hours a week. It was then found that 65 of Internet users fitted the profile typical of addicted subjects, according to DSM-IV criteria (Goldberg 1995). Problematic Internet use is defined as "inability to control one's use of the Internet which leads to negative consequences in daily life", and can be classified in cybersex addiction, cyber relationship addiction, net gaming or net compulsion, information overloaded, and computer addiction (role play videogames) (Scherer 1997, Young 1999, 2001, 2003). Currently, the Internet gaming disorder has been included in the last edition of DSM, the DSM-5 in the section 3 only, and not as a distinct nosological category (APA 2013). 
Nowadays, no precise and validated criteria are still available to diagnose PIU that is reported to have a current prevalence ranging between $3 \%$ and $26 \%$ amongst university students from different countries (Morahan-Martin \& Schumacher 2003, Niemz et al. 2005, Ni et al. 2009, Frangos et al. 2010, Christakis et al. 2011, Canan et al. 2012, Durkee et al. 2012, Li et al. 2015). From the nosological point of view, much disagreement exists as to whether PIU is a behavioral addiction, an impulse control disorder, a subtype of obsessive-compulsive disorder (Shapira et al. 2000, Beard \& Wolf 2001, Davis 2001, Block 2008, Zhang et al. 2008, Tao Huang et al. 2010, Van Rooj et al. 2010, Starcevic 2013, Van Rooj \& Prause 2014, Starcevic \& Billieux 2017), or a maladaptive coping response to stress (Chakraborty et al. 2010, Caselli et al. 2012, Carli et al. 2013, Li et al. 2015). A recent study showed the results of standardized measures and focus group discussions indicating substantial overlap between students' experiences of PIU and signs and symptoms listed in DSM-5 criteria for different disorders, specifically substance use disorder, gambling disorder, and Internet gaming disorder (Li et al. 2016).

Symptoms of PIU encompass those typical of addiction such as craving, dependence, tolerance and abstinence, as well as worries with Internet activities, inability to reduce its use that serves also to reduce stress/anxiety and to increase mood, or to replace other activities and relationships (Lortie \& Guitton 2013, Marazziti et al. 2015). The Internet use may continue in spite of the awareness of the detrimental consequences, and is not recognized to be a problem (Young 1998, Spada 2014, Li et al. 2015). Again, it may be complicated by sleep, seclusion, delay of work, disregard for normal drives, impaired quality of family and social life, problems with partner/friends/relationships, loneliness, loss of real friends/peers/partners (Morahan-Martin \& Schumacher 2003, Dong et al. 2011). Converging data would indicate also that PIU may led to a wide range of negative consequences such as depression (Ko et al. 2010, Park et al. 2013), social phobia or isolation, until the extreme social withdrawal defined by us "technological autism" (Wei et al. 2012, Li et al. 2015), sleeplessness and stress-related disorders (Lam 2014, Li et al. 2015). The sum of sleeplessness and stress system activation following PIU coupled with sedentary life habits has been also related to obesity (Vandelanotte et al. 2009, Lam 2014, Hoare et al. 2016), and to increased attention and cognitive disturbances with poorer school performances amongst students of different nations (Derbyshire et al. 2013, Sernomanci et al. 2014). Further, some studies found an association with substance abuse, self-injurious behavior, increased impulsivity and even suicide attempts (Lam et al. 2009, Yen et al. 2009, Lee et al. 2012, Sun et al. 2012, Li et al. 2015, Baroni et al. 2019).

Given the limited information available in our country, the primary aim of this paper was at investigating the characteristics of Internet use, through latest techno- logies (PCs, smartphones and tablets), amongst Italian University students by means of a specific questionnaire developed by us. The secondary aims were at exploring the presence and prevalence of PIU, and the possible relationships between characterists of Internet use, PIU and different categories of the body mass index (BMI).

\section{SUBJECTS AND METHODS}

A specific interactive platform and website (http://dronet.araneus.it/questionario) on new technologies were created on an external server. The platform allowed access to the self-assessment questionnaire only via the Internet.

On the same time, a self-assessment questionnaire, referred by the acronym QUNT ("Questionario sull'Utilizzo delle Nuove Tecnologie") was developed. The QUNT consists of two sections, one for demographic data and another including 101 items. Forty-five, out of the total 101 items consisted of five possible answers, according to a Likert five-point scale with 1 indicating 'completely false' and 5 indicating 'completely true'; three items were multiple-choice questions; ten were focused on the use of "instant messaging" (with five possible answers, according to a Likert five-point scale with 1 indicating 'completely false' and 5 indicating 'completely true'), and 42 items on the use of "social networks" (instant messaging: whatsapp, telegram, skype, and social networks: facebook, twitter and instagram) (with five possible answers, according to a Likert five-point scale with 1 indicating 'completely false' and 5 indicating 'completely true'). The item \#101 was actually a question on the liking/utility or not the questionnaire.

The items considered of greater relevance were put together in order to identify factors built according to "a priori" criteria extrapolated from the data available in scientific literature (Berad \& Wolf 2001, Caplan 2002, Caselli et al. 2012, Lortie \& Guitton 2013). These factors were "time spent online" (item 2, 3, 4, 5, 6, 7, 25, 33 ), "social withdrawal" (item $8,10,18,22,30,35)$, "abstraction from reality" (item 11, 13, 24), "loss of control" (item 19, 20, 32, 36), "addiction to pornography" (item 26, 27), "ludopathy" (item 40 a-1, 41, 42, $43)$, "addiction to social networks". (49, 50, 51, 52, 53, $54,55,56,57)$. The "addiction to social networks" factor was further divided into the following sub-factors: "addiction to facebook" (item 60 a.d, 61-75), "addiction to twitter" (item 76-86), "addiction to instagram" (item 86-97).

The factor scores were calculated as sum of the scores obtained in each item divided the maximum score in percentage.

We chose the answer 4 (between four and six hours a day) or 5 ( $>$ six hours a day) of item 2 "time spent online", as the cut-off point to identify the possible presence of PIU, according to current literature, although controversies do exist (American Psychiatric Association 2013). 
In collaboration with the Deans of the Universities of Pisa, Brescia and Naples and the Directors, respectively, of the Psychiatric, the Psychology and the Psychiatry Departments of the local Medical schools, an e-mail invitation was sent to all students of all faculties to ask them to complete the questionnaire in the period November 2015 - January 2016. A second mail was sent as a reminder after two months. The access to the questionnaire was possible through email invitation only. In no way, it was possible to identify the participants whose anonymity was warranted.

We obtained the approval from the Ethics Committee of Pisa, the organizing centre, that is considered sufficient also for the other centres. In addition, at the very beginning, the study had already been approved by the Presidenza del Consiglio dei Ministri" of the Italian Government.

\section{Statistical analyses}

The following analyses were used for the primary aims. The independent t-test was applied to compare the mean scores of the factors on the basis of these variables: sex (M/F); single (yes/no); living together (yes/no).

As for the secondary aims, the chi-square analysis was used to compare categorical variables, the prevalence of PIU and its difference between the two sex. The One-Way ANOVA followed by Bonferroni's test for post-hoc was used to assess the comparisons of QUNT factor scores in the four BMI categories.

All statistics were carried out by the Statistical Package for Social Sciences (SPSS), version 22 (IBM Corp. 2013).

\section{RESULTS}

The returned questionnaires were 3324 (6.47\%), of which $1754(51 \%)$ from women and $1570(49 \%)$ from men, out of the total of 51,304 sent to students. They were distributed as follows: 2022 belonging to the
University of Pisa, 798 to that of Brescia, and 326 to that of Naples. The mean age of participants was: $23.4 \pm 5$ years, with no difference between the two sexes (23.4 \pm 4 and $23.3 \pm 5$ years, in men and women, respecttively), or amongst the three centers. The students were evenly distributed amongst the different faculties. In Pisa only, there was a slight, albeit not significant preponderance of students of computer science. Almost all students declared that the smartphone was the most used device to access to Internet.

One thousand nine hundred ten subjects were involved in a love relationship and the remaining 1414 ones were single. Four hundred ten subjects of the first group lived with the partner.

Some significant differences were observed in the QUNT factors according to sex. Generally, men spent more time on line than women, although the difference was not significant (mean score \pm SD: $2.72 \pm 0.70$ vs. $2.69 \pm 0.69$ hours in men and women, respectively; $\mathrm{p}=0.338)$. However, those subjects $(1239,37.3 \%)$ who were probably affected by PIU, according to the set point defined by us (answer 4 or 5 of item \#2), were predominantly men than women $(632,38.8 \%$ vs 497 , $33.3 \%$; $<<0.001$ ) (Figure 1).

The distribution of the QUNT factors was different in the two sexes. Men showed significantly higher scores (mean $\pm \mathrm{SD}$ ) than women at the following factors: "social withdrawal" ( $1.43 \pm 0.48$ vs. $1.33 \pm 0.39, \mathrm{p}<0.001)$; "abstraction from reality" $(1.76 \pm 0.69$ vs. $1.69 \pm 0.62, \mathrm{p}=0.005)$; "loss of control" ( $1.52 \pm 0.57$ vs. $1.46 \pm 0.53, \mathrm{p}=0.002)$; "pornography addiction" ( $2.02 \pm 0.74$ vs. $1.24 \pm 0.46, \mathrm{p}=0.0001)$; "ludopathy" (2.04 \pm 1.07 vs. $1.55 \pm 0.76, \mathrm{p}=0.002)$, and "addiction to twitter" $(1.34 \pm 0.52$ vs. $1.26 \pm 0.45, \mathrm{p}=0.012)$. Women showed higher scores (mean $\pm \mathrm{SD}$ ) than men at the following factors: "addiction to instant messaging" ( $2.88 \pm 0.83$ vs $2.66 \pm 0.82, \mathrm{p}<0.001)$; "addiction to social networks" (SD $2.11 \pm 0.59$ vs $2.00 \pm 0.61, \mathrm{p}<0.001$ ); "addiction to facebook" $(2.11 \pm 0.59$ vs. $2.00 \pm 0.61$ $\mathrm{p}<0.001)$, and "addiction to instagram" $(2.18 \pm 0.73$ vs. $1.96 \pm 0.69$ respectively, $\mathrm{p}<0.001$ ) (Figure 2 ).

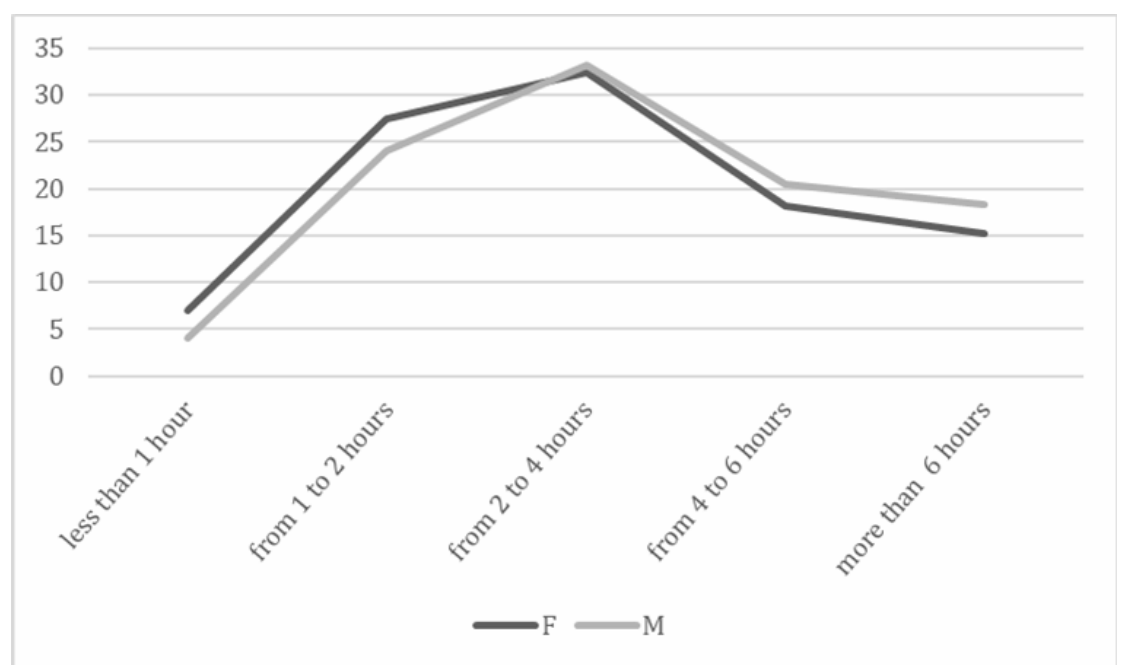

Figure 1. Distribution of the QUNT factors in men and women 


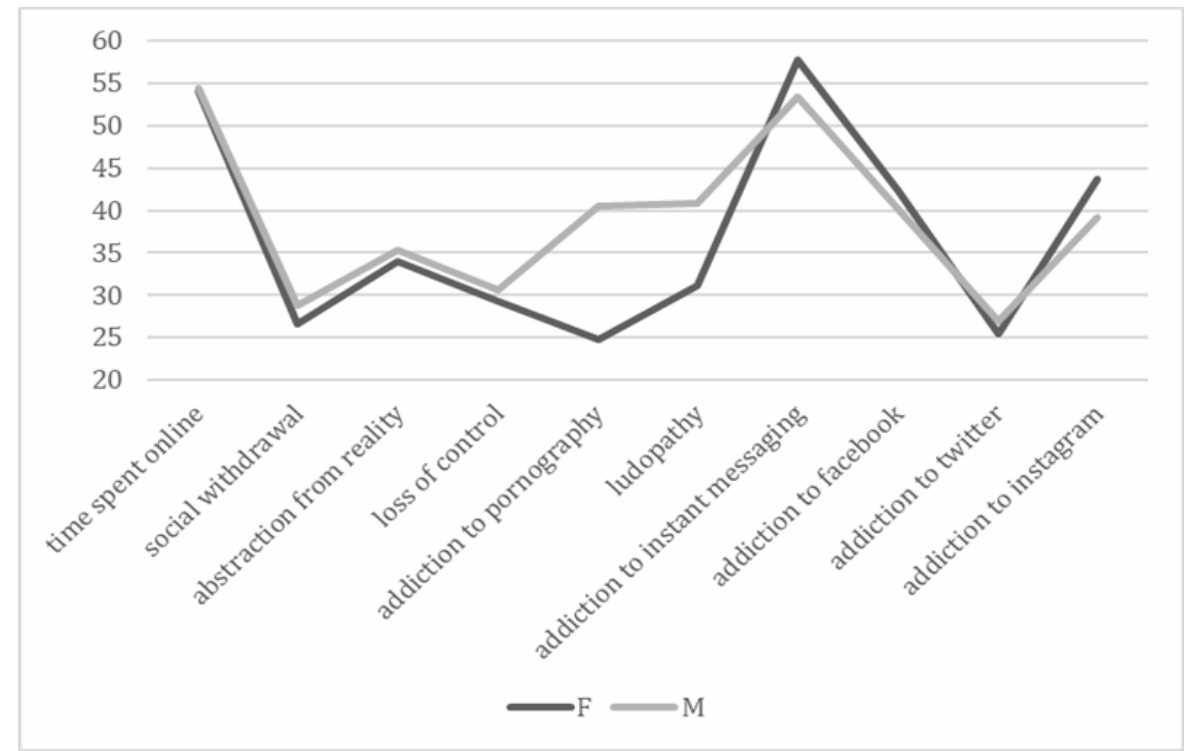

Figure 2. Distribution of the "time spent online" factor in men and women

Table 1. Comparisons of QUNT factor scores in the four BMI categories

Post-hoc comparison:

\begin{tabular}{|c|c|c|c|c|c|c|c|}
\hline Factors & UW & NW & OW & OB & $\mathrm{F}$ & $p$ & $\begin{array}{l}\text { Post-hoc comparison: } \\
\text { significant differences } \\
\quad(p<0.05)\end{array}$ \\
\hline Time spent online & $52.24 \pm 13.58$ & $53.96 \pm 13.17$ & $55.51 \pm 12.77$ & $55.73 \pm 14.54$ & 3.88 & 0.009 & $\mathrm{OW}>\mathrm{UW}$ \\
\hline Social withdrawal & $25.69 \pm 6.65$ & $27.44 \pm 8.61$ & $28.53 \pm 9.74$ & $30.41 \pm 10.04$ & 9.90 & $<0.001$ & $\begin{array}{c}\mathrm{OW}>\mathrm{UW} ; \mathrm{OB}>\mathrm{UW} ; \\
\mathrm{OB}>\mathrm{NW}\end{array}$ \\
\hline Abstraction from reality & $32.48 \pm 11.52$ & $34.46 \pm 13.13$ & $35.31 \pm 13.98$ & $36.01 \pm 13.54$ & 2.68 & 0.045 & none \\
\hline Loss of control & $28.40 \pm 8.81$ & $29.89 \pm 11.12$ & $30.34 \pm 11.39$ & $31.11 \pm 11.81$ & 1.91 & 1.91 & none \\
\hline $\begin{array}{l}\text { Addiction to } \\
\text { pornography }\end{array}$ & $27.12 \pm 11.76$ & $31.79 \pm 14.27$ & $34.97 \pm 14.88$ & $36.38 \pm 16.79$ & 18.66 & $<0.001$ & $\begin{array}{c}\mathrm{NW}>\mathrm{UW} ; \mathrm{OW}>\mathrm{UW} ; \mathrm{OB}> \\
\mathrm{UW} ; \mathrm{NW}>\mathrm{UW} \text {; OW>NW; } \\
\mathrm{OB}>\mathrm{NW} ; \mathrm{OB}>\mathrm{NW}\end{array}$ \\
\hline Ludopathy & $33.06 \pm 17.97$ & $36.03 \pm 18.85$ & $39.68 \pm 22.41$ & $41.06 \pm 23.39$ & 4.26 & 0.005 & $\mathrm{OW}>\mathrm{NW}$ \\
\hline $\begin{array}{l}\text { Addiction to instant } \\
\text { messaging }\end{array}$ & $55.05 \pm 16.33$ & $56.02 \pm 16.47$ & $54.24 \pm 17.36$ & $55.40 \pm 19.09$ & 1.62 & 0.181 & none \\
\hline Addiction to facebook & $41.50 \pm 11.61$ & $41.13 \pm 12.15$ & $41.30 \pm 12.17$ & $43.64 \pm 13.90$ & 1.71 & 0.162 & none \\
\hline Addiction to twitter & $24.17 \pm 5.36$ & $26.00 \pm 9.73$ & $25.98 \pm 10.11$ & $30.80 \pm 12.24$ & 4.97 & 0.002 & $\begin{array}{c}\mathrm{OB}>\mathrm{UW} ; \mathrm{OB}>\mathrm{NW} \\
\mathrm{OB}>\mathrm{OW}\end{array}$ \\
\hline Addiction to instagram & $45.42 \pm 15.28$ & $41.85 \pm 14.70$ & $41.24 \pm 14.03$ & $42.09 \pm 13.45$ & 1.51 & 0.210 & none \\
\hline
\end{tabular}

BMI: body mass index; UW: underweight; normal weight: NW; OW: overweight; OB1: obesity; OB2: second degree of obesity; OB3: third degree of obesity

The analysis of the difference in QUNT factors according to being single or involved in a love relationship led to the following results. Single subjects showed significantly higher scores at the following factors: "time spent online" $(2.75 \pm 0.67$ vs $2.67 \pm 0.64, \mathrm{p}<0.001)$; "social withdrawal" ( $1.40 \pm 0.45$ vs $1.36 \pm 0.42 \mathrm{p}=0.007)$; "abstraction from reality" $(1.80 \pm 0.70$ vs $1.66 \pm 0.62, \mathrm{p}<0.001)$; "loss of control" ( $1.52 \pm 0.76$ vs $1.46 \pm 0.67, \mathrm{p}<0.001)$; "addiction to pornography" ( $1.73 \pm 0.59$ vs $1.52 \pm 0.51$, $\mathrm{p}<0.001)$; "addiction to facebook" $(2.11 \pm 0.64$ vs $2.02 \pm 0.58, \quad \mathrm{p}<0.001)$; and "addiction to twitter" $(1.37 \pm 0.57$ vs $1.24 \pm 0.40, \mathrm{p}<0.001)$.

There were some differences even on "addiction to instant-messaging" "addiction to instagram" factors, but they did not reach the statistical significance.

The analysis of the differences between partners living or not living together (Total: $1910 ; 410$ vs 1500 ) showed some significant differences. The following factors showed higher scores in subjects who did not live with the partner vs those who lived with the partner:" time spent online" (2.69 \pm 0.64 vs $2.58 \pm 0.66$, $\mathrm{p}=0.004)$; "addiction to pornography" $(1.53 \pm 0.67$ vs $1.45 \pm 0.67, \quad \mathrm{p}=0.047)$; "ludopathy" ( $1.81 \pm 0.95$ vs $1.74 \pm 0.97, \mathrm{p}=0.007)$; and "addiction to facebook" ( $2.03 \pm 0.59$ vs $1.96 \pm 0.54, \mathrm{p}=0.033)$.

The total sample was then subdivided according to the common BMI $\left(\mathrm{kg} / \mathrm{m}^{2}\right)$ categories. One hundred eightyone subjects had a BMI less than 18.50 (underweight, UW); 2481 between 18.51 and 24.9 (normal weight, NW); 517 between 25 and 30 (overweight, OW); 106 between 30.1 and 34.9 (first degree of obesity, OB1); 29 between 35 and 39.9 (second degree of obesity, OB2); and 9 greater than 40 (third degree of obesity, OB3). The categories OB1, OB2 and OB3 were merged in the 

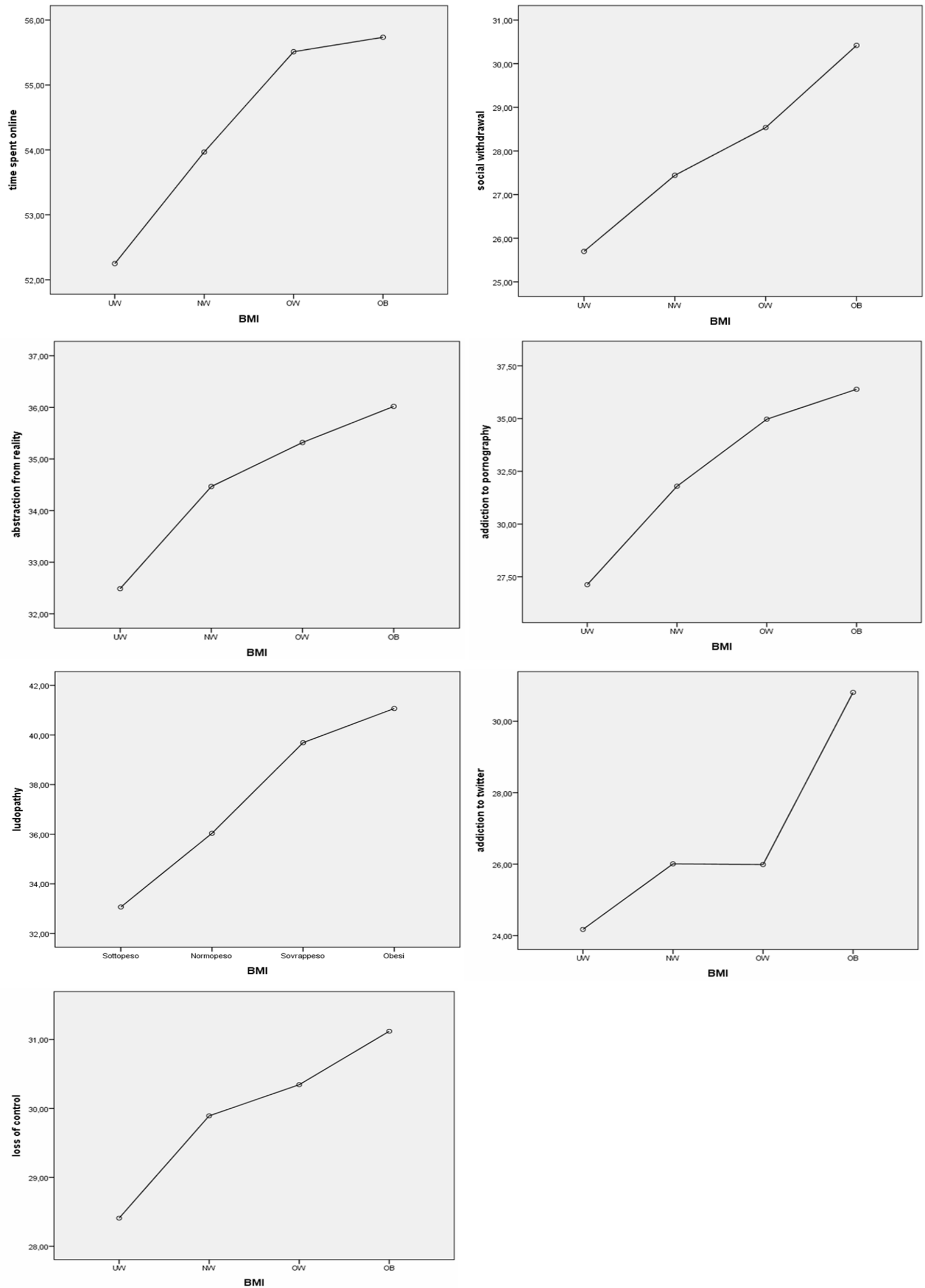

Figure 3. Trend of the percentage scores of the seven QUNT factors 
category "Obese" (OB). The comparisons of QUNT factor scores in the four BMI categories are reported in table 1 that shows that the greater the BMI the greater the score, although significant differences did not exist for all categories and factors. Moreover, the panels of figure 3 depict the trend of the percentage scores of the seven factors, hence indicating that the higher the score of the factors "time spent online", "social withdrawal", "abstraction from reality", "loss of control", "addiction to pornography", "ludopathy", "addiction to twitter", the higher the BMI. Even the factor "addiction to facebook" showed a trend towards higher score in the OB vs NW individuals (Figure 3).

\section{DISCUSSION}

The present study is the result of a collaborative survey exploring the prevalence and the characteristics of Internet use by new technologies (PCs, smartphones and tablets), as well as of PIU, amongst University students. Indeed, this population is particularly vulnerable to abuse them, given their increasing use in university settings that now has reached $100 \%$ of the students (Miniwatts Marketing Group 2017).

Two university centers were selected on the basis of their geographical locations (Northern and Southern Italy, Brescia and Naples, respectively) by the coordinating center, Pisa that is located in central Italy, in order to obtain data from different Italian areas. Several students of all faculties received the invitation by their secretariats to fill a questionnaire, the so-called QUNT ("Questionario sull'Utilizzo delle Nuove Tecnologie"), developed by us for this specific purpose. The QUNT item "time spent online" was considered crucial to identify PIU when it was $>$ four hours a day (answer 4 or 5).

About $7 \%$ of the students (3324 out of the total of 51,304 who received the QUNT surveys) returned them correctly filled: this response rate was quite low and might have have affected the representativeness of the results. There was a preponderance (2022) of students belonging to Pisa University, a number significant higher than that (798) of Brescia and (326) of Naples: this can be ascribed to the specific advertisings carried out by the general secretariat of Pisa University and by the local newspapers emphasizing the survey. In the three centres, both sexes were equally represented. Similarly, there was an even distribution of responses amongst the different faculties.

Not surprisingly, almost all participants reported that the access to Internet is achieved mostly by smartphones.

When the distribution of QUNT factors was analyzed according to sex, some significant differences emerged. Indeed, men showed higher scores than women at different factors, such as "social withdrawal", "abstraction from reality", "loss of control", "pornography addiction", "ludopathy" and "addiction to twitter". Women had higher scores than men on "addiction from instant messaging", "addiction from social networks", "addiction to facebook", and "addiction to instagram". Therefore, it seems that women use new technologies more for creating and maintaining social relationships, while men for entertainment and passing time (Ryan et al. 2014). Interestingly, in a group of drug addicts such differences were not present, as if abused drugs provoked a sort of "flattening" effects decreasing some sex-related characteristics (Baroni et al. 2019).

The results showed also that $37 \%$ of students gave the answer 4 or 5 (between 4 and 6 hours a day and $>$ six hours a day, respectively) at the item \#2 ("time spent online"), suggestive of PIU. This percentage is higher than those reported in the available literature amongst university students that is very heterogeneous, while ranging between $1 \%$ to $26.3 \%$ (Niemz et al. 2005 , Ni et al. 2009, Canan et al. 2012, Durkee et al. 2012, Li et al. 2015). However, it should be underlined, that the selection criteria of the students in the published studies were quite different, as they were the questionnaires (Moreno et al. 2011, Jelenchick et al. 2012). Another major bias is that generally the subjects were recruited within the same university, while in our study we included students belonging to three different centers (Fortson et al. 2007). Again, it is also true that PIU is an increasing problem that should be considered an epidemic and our study reflects more updated and realistic scenarios. Not surprisingly, we observed a preponderance of PIU amongst male students, in agreement with other data gathered in different countries (Anderson et al. 2005, Ni et al. 2009, Frangos et al. 2010, Li et al. 2015).

Some significant differences were also present in being single vs being involved in a love relationship, with no sex difference. Not surprisingly, single subjects spent more time online, and showed higher scores at factors suggestive of Internet usage for passing time or for recreation, such as "social withdrawal", "abstraction from reality", "loss of control" "addiction to pornography", "addiction to facebook", and "addiction to twitter" factors.

A large percentage of single male subjects (72\%) answered 4 or 5 at the item \#4: this would hence support a vulnerability of this sex to PIU when it is coupled with being single. These findings would indicate that a highly emotional loving relationship might in some way prevent subjects, especially if male, from becoming excessive or problematic Internet users. The "protective" impact of a love relationship is again supported by our finding reporting that those subjects living with their partners show lower scores at "time spent online", addiction to pornography", "gambling addiction", and "addiction to facebook" factors (Tucker 2015).

The comparisons of the QUNT factor score percentages in the BMI categories led to intriguing results. Indeed, obesity (assessed by the standard BMI values and including in one category only all subjects from the first to third degree of obesity) led to higher scores of "time spent online", "social withdrawal", "abstraction from reality" and "loss of control" factors: that is to say, 
the more obese the subjects, the higher the scores. Previous studies already highlighted that video gaming and excessive Internet usage is associated with poor physical activity (Marshall et al. 2004) and bad dieting habits (Park et al. 2010). Therefore, it is evident that Internet use may promote sedentary behaviors (Hoare et al. 2016) that may give raise to that vicious circle at the basis of several metabolic and mental disorders that may be also intertwined (Catena Dell'Osso et al. 2013, Sridar $\&$ Sanjiana 2016). Reduced sleeping time and disrupted circadian rhythms are other factors that may increase the probability of the same disorders (Lam 2014, Li et al. 2015), as well as of decline of school performances (Derbyshire et al. 2013, Sernomanci et al. 2014).

Our study has some limitations that should be acknowledged. First, the QUNT questionnaire was not validated, although this is quite common in studies in this field (Niemz et al. 2005, Ni et al. 2009, Canan et al. 2012, Durkee et al. 2012, Li et al. 2015). Second, the response rate was low and might have influenced the ensuing data and their generalizability. Third, the prevalence of PIU was inferred from one item only, but it was a corollary of the main objective of the study exploring primarily the characteristics of Internet use. Fourth, no information was gathered on emotional distress, or associated mental disorders, substance abuse and disturbed behaviours that are currently under investigation.

\section{CONCLUSIONS}

The findings of our study show that very often the usage of Internet through new technologies, especially smartphones, amongst a large sample of students from three major Italian universities may exceeds their real use, as the majority of the subjects resulted to spend online an excessive period of time and about one third (37.3\%) a "pathological" time. There were some gender differences, as male subjects were more involved in online recreational activities, as shown by a series of factors identified by the QUNT, while female subjects were more addicted to instant messaging and generally to social networks. For this reason, male subjects, especially if single or not living together with their partners showed more propensity to social withdrawal, to gaming online, to reduce real contacts with peers and, in ultimate analysis to PIU.

The relationship between time spent online (and related sedentary life style) and BMI would suggest that the Internet use might be one of the factors the basis of increasing weight gain and obesity amongst adolescents and young adults worldwide (Vandelanotte et al. 2009, Hoare et al. 2016). Therefore, preventive strategies of Internet misuse should be rapidly implemented to avoid the possibility not only of physical changes that may lead to severe metabolic and cardiovascular disorders, or psychological/psychiatric disorders, but also, as pavented by some researchers, to an irreversible "mind change" of next generations that can be detrimental for the future of our species (Greenfield 2015).

\section{Acknowledgements:}

This study was supported by "Presidenza del Consiglio dei Ministri" of the Italian Government (grant IAD-U).

Conflict of interest: None to declare.

\section{Contribution of individual authors:}

Donatella Marazziti: study design, data collection, first draft, approval of the final version.

Stefano Baroni: study design, data collection, first draft. Federico Mucci: data collection, first draft.

Armando Piccinni, Alberto Ghilardi, Andrea Fiorillo, Mario Luciano, Gaia Sampogna \& Ilenia Moroni: data collection.

Gabriele Massimetti: statistical analysis.

Liliana Dell'Osso: study design, data collection.

\section{References}

1. American Psychiatric Association: Diagnostic and Statistical Manual of Mental Disorders (DSM-5, 5th edition). Arlington, VA: American Psychiatric Publishing, 2013

2. Anderson KJ: Internet use among college students: An exploratory study. J Am Coll Health 2001; 50:21-26. doi:10.1080/07448480109595707

3. Baroni S, Marazziti D, Mucci F, Diadema E \& Dell'Osso L: Problematic Internet use in drug addicts under treatment in public rehab centers. World J Psychiatry 2019; 9:55-64. doi:10.5498/wjp.v9.i3.55

4. Beard $K W$ \& Wolf EM: Modification in the proposed diagnostic criteria for internet addiction. Cyberpsychol Behav 2001; 4:377-383.

doi:10.1089/109493101300210286

5. Block JJ: Issues for DSM-V: Internet addiction. Am J Psychiatry 2008; 165:306-307. doi:10.1176/appi.ajp.2007.07101556

6. Canan F, Ataoglu A, Ozcetin A \& Icmeli C: The association between internet addiction and dissociation among turkish college students. Compr Psychiatry 2012; 53:422426. doi:10.1016/j.comppsych.2011.08.006

7. Caplan SE: Problematic Internet use and psychosocial well-being: development of a theory-based cognitive-behavioral measurement instrument. Comput Human Behav 2002; 18:553-575. doi:10.1016/S0747-5632(02)00004-3

8. Carli V, Durkee T, Wasserman D, Hadlaczky G, Despalins $R$, Kramarz E, et al: The association between pathological internet use and comorbid psychopathology: A systematic review. Psychopathology 2013; 46:1-13. doi: 10.1159/000337971

9. Caselli $G$, Soliani $M \&$ Spada MM: The effect of desire thinking on craving: An experimental investigation. Psychol Addict Behav 2013; 27:301-306. doi:10.1037/a0027981

10. Catena-Dell'Osso M, Rotella F, Dell'Osso A, Fagiolini A \& Marazziti D: Inflammation, serotonin and major depression. Curr Drug Targets 2013; 14:571-577

11. Chakraborty K, Basu D \& Vijaya Kumar KG: Internet addiction: Consensus, controversies, and the way ahead. East Asian Arch Psychiatry 2010; 20:123-132 
12. Christakis DA, Moreno MM, Jelenchick L \& Myaing MT, Zhou C: Problematic internet usage in us college students: A pilot study. BMC Med 2011; 9:77. doi:10.1186/1741-7015-9-77

13. Christakis DA: Internet addiction: A 21st century epidemic? BMC Med 2010;8:61. doi:10.1186/1741-7015-8-61

14. Council On C: Media: Media and young minds. Pediatrics 2016; 138. doi:10.1542/peds.2016-2591

15. Davis R: A cognitive-behavioral model of pathological Internet use. Comput Human Behav 2001; 17:187-195. doi:10.1016/s0747-5632(00)00041-8

16. Derbyshire KL, Lust KA, Schreiber LR, Odlaug BL, Christenson GA, Golden DJ, et al: Problematic internet use and associated risks in a college sample. Compr Psychiatry 2013; 54:415-422. doi:10.1016/j.comppsych.2012.11.003

17. Dong G, Lu Q, Zhou H \& Zhao X: Precursor or sequela: Pathological disorders in people with internet addiction disorder. PLoS One 2011; 6:e14703. doi:10.1371/journal.pone.0014703

18. Durkee T, Kaess M, Carli V, Parzer P, Wasserman C, Floderus B, et al: Prevalence of pathological internet use among adolescents in europe: Demographic and social factors. Addiction 2012; 107:2210-2222. doi:10.1111/j.1360-0443.2012.03946.x

19. Fortson BL, Scotti JR, Chen YC, Malone J \& Del Ben KS: Internet use, abuse, and dependence among students at a southeastern regional university. J Am Coll Health 2007; 56:137-144. doi: 10.3200/JACH.56.2.137-146

20. Frangos $C$, Frangos $C \&$ Kiohos A: Internet addiction among Greek university students: Demographic associations with the phenomenon, using the Greek version of Young's Internet addiction test. Int J Econ Sc App Res 2010; 3:49-74

21. Goldberg I: Internet addictive disorder (IAD) diagnostic criteria, 1995. Available at: www.psycom.net/iadcriteria.html. Accessed: 2017 Jul 31

22. Greenfield S: Mind change: how digital technologies are leaving their mark on our brains. New York, Random House, 2015

23. Hoare E, Milton K, Foster C\& Allender S: The associations between sedentary behaviour and mental health among adolescents: a systematic review. Int J Behav Nutr Phys Act 2016; 108. doi:10.1186/s12966-016-0432-4

24. IBM Statistical Package for Social Sciences (SPSS) for Windows and Macintosh, Version 22.0. Armonk, NY: IBM Corp., 2013

25. Jelenchick LA, Becker $T$ \& Moreno MA: Assessing the psychometric properties of the internet addiction test (iat) in us college students. Psychiatry Res 2012; 196:296-301. doi:10.1016/j.psychres.2011.09.007

26. Kerkhof P, Finkenauer C\& Muusses LD: Relational consequences of compulsive internet use: a longitudinal study among newlyweds. Hum Commun Res 2011; 37:147-173. doi:10.1111/j.1468-2958.2010.01397.x

27. Ko CH, Yen JY, Yen CF, Chen CS \& Chen CC: The association between internet addiction and psychiatric disorder: A review of the literature. Eur Psychiatry 2012; 27:1-8. doi:10.1016/j.eurpsy.2010.04.011

28. Kuss DJ, Griffiths MD, Karila L \& Billieux J: Internet addiction: A systematic review of epidemiological research for the last decade. Curr Pharm Des 2014; 20:4026-4052
29. Lam LT, Peng Z, Mai J \& Jing J: The association between internet addiction and self-injurious behaviour among adolescents. Inj Prev 2009; 15:403-408. doi:10.1136/ip.2009.021949

30. Lam LT: Internet gaming addiction, problematic use of the internet, and sleep problems: A systematic review. Curr Psychiatry Rep 2014; 16:444.

doi:10.1007/s11920-014-0444-1

31. Lee HW, Choi JS, Shin YC, Lee JY, Jung HY \& Kwon JS: Impulsivity in internet addiction: A comparison with pathological gambling. Cyberpsychol Behav Soc Netw 2012; 15:373-377. doi:10.1089/cyber.2012.0063

32. Li W, O'Brien JE, Snyder SM \& Howard MO: Characteristics of internet addiction/pathological internet use in u.S. University students: A qualitative-method investigation. PLoS One 2015; 10:e0117372. doi:10.1371/journal.pone.0117372

33. Li W, O'Brien JE, Snyder SM \& Howard MO: Diagnostic criteria for problematic internet use among u.S. University students: A mixed-methods evaluation. PLoS One 2016; 11:e0145981. doi:10.1371/journal.pone.0145981

34. Lortie CL \& Guitton MJ: Internet addiction assessment tools: Dimensional structure and methodological status. Addiction 2013; 108:1207-1216.

doi:10.1111/add.12202

35. Marazziti D, Presta S, Baroni S, Silvestri $S$ \& Dell'Osso L: Behavioral addictions: A novel challenge for psychopharmacology. CNS Spectr 2014; 19:486-495. doi:10.1017/S1092852913001041

36. Marshall SJ, Biddle SJ, Gorely T, Cameron N \& Murdey I: Relationships between media use, body fatness and physical activity in children and youth: A meta-analysis. Int J Obes Relat Metab Disord 2004;28:1238-1246. doi:10.1038/sj.ijo.0802706

37. Miniwatts Marketing Group: Internet world stats: usage and population statistics, 2017. Available at: http://www.internetworldstats.com/stats.htm. Accessed: 2017 Jul 31.

38. Morahan-Martin J \& Schumacher P: Lonliness and social uses of the Internet. Comput Human Behav 2003;16:659671. doi:10.1016/S0747-5632(03)00040-2

39. Moreno MA, Jelenchick L, Cox E, Young $H \&$ Christakis DA: Problematic internet use among us youth: A systematic review. Arch Pediatr Adolesc Med 2011; 165:797-805. doi:10.1001/archpediatrics.2011.58

40. Ni X, Yan H, Chen S\& Liu Z: Factors influencing internet addiction in a sample of freshmen university students in china. Cyberpsychol Behav 2009; 12:327-330. doi:10.1089/cpb.2008.0321

41. Niemz K, Griffiths M \& Banyard P: Prevalence of pathological internet use among university students and correlations with self-esteem, the general health questionnaire (ghq), and disinhibition. Cyberpsychol Behav 2005; 8:562-570. doi:10.1089/cpb.2005.8.562

42. Park HS, Kim SH, Bang SA, Yoon EJ, Cho SS \& Kim SE: Altered regional cerebral glucose metabolism in internet game overusers: A 18f-fluorodeoxyglucose positron emission tomography study. CNS Spectr 2010; 15:159-166

43. Park S, Hong KE, Park EJ, Ha KS, Yoo HJ: The association between problematic internet use and depression, suicidal ideation and bipolar disorder symptoms in korean adolescents. Aust N Z J Psychiatry 2013; 47:153-159. doi:10.1177/0004867412463613 
44. Reid Chassiakos YL, Radesky J, Christakis D, Moreno MA, Cross C \& Council On C: Media: Children and adolescents and digital media. Pediatrics 2016; 138. doi:10.1542/peds.2016-2593

45. Ryan T, Chester A, Reece $J$ \& Xenos $S$ : The uses and abuses of facebook: A review of facebook addiction. J Behav Addict 2014; 3:133-148. doi:10.1556/JBA.3.2014.016

46. Scherer K: College life on-line: Healthy and unhealthy Internet use. J Coll Stud Dev 1997;38:655-665.

47. Senormanci O, Saracli O, Atasoy N, Senormanci G, Kokturk $F \&$ Atik L: Relationship of internet addiction with cognitive style, personality, and depression in university students. Compr Psychiatry 2014; 55:1385-1390. doi:10.1016/j.comppsych.2014.04.025

48. Shapira NA, Lessig MC, Goldsmith TD, Szabo ST, Lazoritz M, Gold MS, et al: Problematic internet use: Proposed classification and diagnostic criteria. Depress Anxiety 2003; 17:207-216. doi:10.1002/da.10094

49. Spada MM: An overview of problematic internet use. Addict Behav 2014; 39:3-6. doi:10.1016/j.addbeh.2013.09.007

50. Sridhar GR \& Sanjana NS: Sleep, circadian dysrhythmia, obesity and diabetes. World J Diabetes 2016; 7:515-522

51. Starcevic $V \&$ Billieux J: Does the construct of Internet addiction reflect a single entity or aspectrum of disorders? Clinical Neuropsychiatry 2017;14:5-10

52. Starcevic V: Is internet addiction a useful concept? Aust $N$ Z J Psychiatry 2013; 47:16-19. doi:10.1177/0004867412461693

53. Sun P, Johnson CA, Palmer P, Arpawong TE, Unger JB, Xie B, et al: Concurrent and predictive relationships between compulsive internet use and substance use: Findings from vocational high school students in china and the USA. Int J Environ Res Public Health 2012; 9:660-673. doi:10.3390/ijerph9030660

54. Tao R, Huang $X$, Wang J, Zhang H, Zhang $Y \&$ Li M: Proposed diagnostic criteria for internet addiction. Addiction 2010; 105:556-564. doi:10.1111/j.1360-0443.2009.02828.x

55. Tucker J: The healing power of love. J Fam Health 2015; 25:23-26

56. Valkenburg PM \& Peter J: Online communication among adolescents: An integrated model of its attraction, opportunities, and risks. J Adolesc Health 2011; 48:121127. doi:10.1016/j.jadohealth.2010.08.020

57. Van Rooij AJ \& Prause N: A critical review of "internet addiction" criteria with suggestions for the future. J Behav Addict 2014; 3:203-213. doi:10.1556/JBA.3.2014.4.1

58. van Rooij AJ, Schoenmakers TM, van de Eijnden RJ \& van de Mheen D: Compulsive internet use: The role of online gaming and other internet applications. $J$ Adolesc Health 2010; 47:51-57. doi:10.1016/j.jadohealth.2009.12.021

59. Vandelanotte $C$, Sugiyama T, Gardiner $P \&$ Owen $N$ : Associations of leisure-time internet and computer use with overweight and obesity, physical activity and sedentary behaviors: Cross-sectional study. J Med Internet Res 2009; 11:e28. doi:10.2196/jmir.1084

60. Wei H-T, Chen M-H, Huang P-C \& Bai Y-M: The association between online gaming, social phobia, and depression: an internet survey. BMC Psychiatry 2012; 12:92. doi:10.1186/1471-244X-12-92

61. Yen JY, Ko CH, Yen CF, Chen CS \& Chen CC: The association between harmful alcohol use and internet addiction among college students: Comparison of personality. Psychiatry Clin Neurosci 2009; 63:218-224. doi:10.1111/j.1440-1819.2009.01943.x

62. Young KS: A Therapist's Guide to Assess and Treat Internet Addiction, 2003. Available at: http://www.netaddiction.com/articles/practitioners.pdf

63. Young KS: Caught in the net: how to recognize the signs of Internet addiction - and a winning strategy for recovery. New York, J. Wiley, 2001

64. Young KS: Internet addiction: Symptoms, evaluation, and treatment; in Vande-Creek L, Jackson T (eds): Innovations in clinical practice: a source book. Sarasota, FL: Professional Resource Press, 1999

65. Young KS: Internet Addiction: The emergence of a new clinical disorder. Cyberpsychol Behav 1998; 1:237-244. doi:10.1089/cpb.1998.1.237

66. Zhang L, Amos C\& McDowell WC: A comparative study of internet addiction between the united states and china. Cyberpsychol Behav 2008; 11:727-729. doi:10.1089/cpb.2008.0026

Correspondence:

Donatella Marazziti, MD

Dipartimento di Medicina Clinica e Sperimentale, University of Pisa

Via Roma 67, 56100 Pisa, Italy

E-mail:dmarazzi@psico.med.unipi.it 